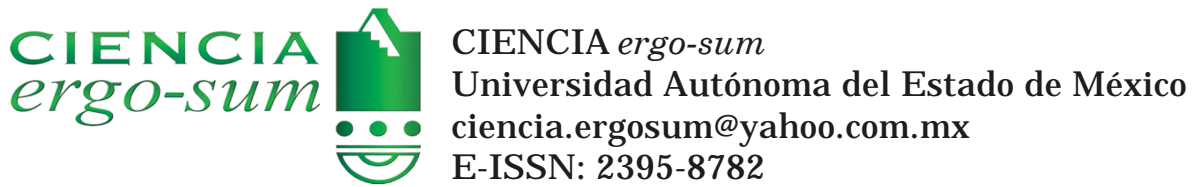

\title{
Borg's category ratio-scale (CR-10) is useful to predict the onset of blood lactate accumulation (OBLA) in young Mexicans adults, regardless their body mass
}

Ramos J iménez, Arnulfo; Wall Medrano, Abraham; Hernández Lepe, Marco A.; Chávez Treviño, Gregorio;

Guereca Arvizuo, J aime y Hernández Torres, Rosa Patricia

Borg's category ratio-scale (CR-10) is useful to predict the onset of blood lactate accumulation (OBLA) in young

Mexicans adults, regardless their body mass

CIENCIA ergo-sum, vol. 26, núm. 1, marzo-junio 2019|e42

Universidad Autónoma del Estado de México, México

Esta obra está bajo una Licencia Creative Commons Atribución-NoComercial-SinDerivar 4.0 Internacional.

Ramos J iménez, A.; Wall Medrano, A., Hernández Lepe, M. A., Chávez Treviño, G., Guereca Arvizuo, J . y Hernández Torres, R. P. (2018). Borg's category ratio-scale (CR-10) is useful to predict the onset of blood lactate accumulation (OBLA) in young Mexicans adults, regardless their body mass. CIE NCIA ergo-sum, 25 (3). https://doi.org/10.30878/ces.v26n1a7 


\title{
Borg's category ratio-scale $(\mathrm{CR}-10)$ is useful to predict the onset of blood lactate accumulation (OBLA) in young Mexicans adults, regardless their body mass
}

La escala Borg (CR-10) sirve para predecir el inicio de la acumulación de lactato sanguíneo (OBLA) en adultos jóvenes mexicanos, independientemente de su masa corporal

\author{
Arnulfo Ramos Jiménez \\ Universidad Autónoma de Ciudad Juárez, México \\ aramos@uacj.mx \\ Abraham Wall Medrano \\ Universidad Autónoma de Ciudad Juárez, México \\ awall@uacj.mx \\ Marco Antonio Hernández Lepe \\ Universidad Autónoma de Ciudad Juárez, México \\ qblepe@hotmail.com \\ Gregorio Chávez Treviño \\ Universidad Autónoma de Ciudad Juárez, México \\ al150609@alumnos.uacj.mx \\ Jaime Guereca Arvizuo \\ Universidad Autónoma de Chibuahua, México \\ jaime.guereca@uacj.mx \\ Rosa Patricia Hernández Torres \\ Universidad Autónoma de Chibuahua, México \\ rphernant@yahoo.com
}

\begin{abstract}
Aim: To evaluate the predictive value of Borg's category ratio-scale (CR-10; $1-10)$ toward the onset of blood lactate accumulation (OBLA). Methods: 91 young Mexicans performed three non-consecutive sub-maximal exercise tests. Heart rate (HR), blood lactate and oxygen uptake were recorded at each CR-10 rating. Regression equations, reliable HR and CR-10 cut-off points of OBLA were then calculated. Results: HR (86 beats/min) and CR-10 (4.5) predicted OBLA with the same certainty, regardless the subject's body mass. CR-10, HR and oxygen uptake, independently explained more than $60 \%$ of the associated variance to OBLA. Conclusions: CR-10 is useful to predict OBLA with almost the same certainty that HR, regardless the subject's body mass.
\end{abstract}

KEYWORDS: exercise physiology, metabolism, obesity, physical fitness, youth.

\section{RESUMEN}

Objetivo: evaluar el valor predictivo de la escala de Borg (CR-10; 1 -10) para el inicio de la acumulación de lactato en sangre (OBLA). Métodos: 91 jóvenes mexicanos realizaron tres pruebas de ejercicio submáximas no consecutivas. La frecuencia cardíaca (FC), el lactato en sangre y el consumo de oxígeno se registraron en cada determinación del CR-10. Se calcularon ecuaciones de regresión y los puntos de corte de FC y al OBLA. Resultados: La FC (86 lat/min) y el CR-10 (4.5) predijeron el OBLA con la misma certeza, independientemente de la masa corporal del sujeto. CR-10, la FC y el consumo de oxígeno explicaron independientemente más de 60\% de la varianza asociada al OBLA. Conclusiones: CR-10 es útil para predecir el OBLA con casi la misma certeza que la FC, independientemente de la masa corporal del sujeto.

Palabras Clave: fisiología del ejercicio, metabolismo, obesidad, aptitud física, juventud. 


\section{INTRODUCTION}

Overweight/obesity [body mass index $\geq 25 \mathrm{~kg} / \mathrm{m}^{2}$ ] is a prodromal condition for many metabolic derangements closely related to several non-communicable chronic diseases in young adults around the globe, including Mexicans (Wall-Medrano et al., 2016). The Mexican government is pushing for a more "ecological/systemic" agenda to reduce the economic burden associated to this condition, implementing structural (e.g. primary prevention of chronic diseases and taxation of energy-dense foods), physical (e.g. exercise equipment in public spaces), communication (e.g. front package nutrition labelling) and surveillance (e.g. 6 year-spaced health \& nutrition surveys) policies. A high rate of sedentarism has contributed to the alarming rates of obesity in young Mexicans but multi-stakeholder organizations have financed several programs to promote physical activity, in order to reduce this unhealthy behavior (Jauregui et al. 2015). Effective weight-loss programs often include personalized counseling and prescription of systematic physical activity, being aerobic exercise in private facilities the most common. According to the 2016 International Fitness Industry Trend Report (Club Intel, 2016), high intensity interval exercise, group cycling (constant intensity), spinning (incremental intensity) and traditional yoga classes have reached the "mature state" as exercising strategies for people with normal and excess body weight.

However, health organizations such as the American College of Sports Medicine, American College of Chest Physicians, American Heart Association and the American Thoracic Society, recommend several standards for exercise prescription prior to its systematic performance (American Thoracic Society, 2003; Fletcher et al., 2013), a fact that is not followed in most fitness centers. From a primary and secondary prevention stand point, exercise prescription should be initially based on people's fitness parameters which differ by age, gender and body weight status (Edvardsen et al., 2014; Loe et al.2013). Specifically, the physical performance under submaximal exercise tests using stationary bicycles, treadmills and cycle-ergometers is commonly evaluated in clinical and research settings by measuring people's heart rate $(\mathrm{HR})$, maximal oxygen uptake $\left(\mathrm{VO}_{2}\right.$ max $)$ and respiratory exchange ratio $\left(\mathrm{VCO}_{2} / \mathrm{VO}_{2}\right)$, since all of them show a parallel increase with exercise intensity, reaching a steady state at a submaximal workload (Jones et al., 1985; Ramos-Jiménez et al., 2008). These physiological parameters objectively evaluate the body's maximal aerobic capacity and so, more reliable and safe exercise protocols can be prescribed (American Thoracic Society, 2003; Fletcher et al., 2013).

Blood lactate $\left(\left[\mathrm{LA}^{-}\right]_{\mathrm{b}}\right)$ has been also used in exercise testing (Beneke et al., 2011) since it is very sensitive to exercise intensity and duration and it is also useful to evaluate the passive and active recovery post-exercise (Ramos-Jiménez et al., 2013a). The onset of blood lactate accumulation (OBLA) occurs at $\left[\mathrm{LA}^{-}\right]_{\mathrm{b}}=4 \mathrm{mM}$ and encompasses the psychomotor fatigue threshold, a sign of metabolic response to exercise tolerance and endurance training (Chmura \& Nazar, 2010). However, without acknowledging their usefulness, the abovementioned fitness parameters are time $\&$ resource consuming for fitness centers.

The relationship between self-perceived physical exertion (PE), $\mathrm{HR}, \mathrm{VO}_{2} \max$ and $\left[\mathrm{LA}^{-}\right]_{\mathrm{b}}$ in heavy indoor exercising has been well stablished (Borg, 1982; Ramos-Jiménez et al., 2013b). Among PE scales, the ten-point Borg's category ratio-scale (CR-10) increases linearly with HR while its relationship with submaximal workload, perception of leg pain, anaerobic threshold and $\left[\mathrm{LA}^{-}\right]_{\mathrm{b}}$ follows a non-lineal function (Borg et al., 1985; Zamunér et al., 2011). Although Borg \& Kaijser (2006) have developed other PE scales initially proposed to give data that grow linearly with stimulus intensity (e.g. $\mathrm{HR}$ and $\mathrm{VO}_{2}$ in aerobic work of steady-state character on a cycle-ergometer) within the 4-6 min after initiation but CR-10 seems to fit more properly with $\left[\mathrm{LA}^{-}\right]_{\mathrm{b}}$ and the anaerobic threshold (attained at $\mathrm{a}\left[\mathrm{LA}^{-}\right]_{\mathrm{b}}$ higher than OBLA and where its clearance is reduced) in incremental cycle-ergometer tests (Muyor, 2013; Zamunér et al., 2011). Moreover, CR-10 is particularly useful in clinical settings and epidemiological studies to evaluate programmed exercising and recreational physical activity.

However, the reliability of CR-10 to predict $\left[\mathrm{LA}^{-}\right]_{\mathrm{b}}$ levels depends on the type of exercise (e.g. valid for bench stepping but not aerobic dance; Muyor, 2013) and adequate large-scale validations on this matter have 
not been reported yet. Moreover, it is well known that non-proper (self-selected or prescribed) exercise intensity affects PE in overweight/obese (endomorph) subjects, reducing their motivation and adherence to any exercise program (Ekkekakis \& Lind, 2006), a fact that could be minimized with the timely detection of pre-maximal PE in people with excess body weight. This study aimed to take a step forward on the validity of CR-10 to predict OBLA, since OBLA precedes maximal PE and is the breaking point on body fuel utilization (from fat to carbohydrates), determining an efficient weight-loss. Convergent validity of CR-10 against $\mathrm{HR}$ and prospective equations to predict and $\left[\mathrm{LA}^{-}\right]_{\mathrm{b}}$ is also reported.

\section{Materials and methods}

\section{1. Experimental design}

An observational cross-sectional study was performed from January-April 2017. The Strengthening the Reporting of Observational studies in Epidemiology statement was considered when drafting this report.

\subsection{Subjects and setting}

One hundred and thirty college students $(24 \pm 4 \mathrm{y})$ were enrolled in the study. Since the physiological response (e.g. body temperature, blood pressure and HR) to exercise is gender-specific in this type of population (Loe et al., 2013; Ramos-Jiménez et al., 2013b), just male subjects were included. Other inclusion criteria were a stable body weight in the last month, not have smoked, drunk alcohol and consumed any drug nor sport supplement six months before participation. No participant reported a dangerous health condition in the physical activity readiness questionnaire (Dinger et al., 2006). Ninety-one participants fulfilled these criteria and were formerly enrolled in the study. $85 \%$ of all participants spent $\leq 3 \mathrm{~h}$ /week to moderate-vigorous physical activity while $15 \%$ were athletes out of competition season. All participants underwent a physical examination and were instructed to avoid moderate-to-high physical activity $48 \mathrm{~h}$ before any session. All experiments were performed in a wellventilated laboratory at standard room conditions $\left(23^{\circ} \mathrm{C}\right.$ and $23 \%$ of relative humidity).

\section{AnTHRopometry \& BODY COMPOSITION}

Each participant came to the laboratory between 8:00 - 10:00, either fasted or having eaten a light standard breakfast (25-30\% of the subject's daily energy requirement) in five separate $(72 \mathrm{~h})$ occasions during two and a half weeks. Body weight $(\mathrm{kg}) \&$ height $(\mathrm{m})$ (test-retest, $r=0.98)$ and waist $\&$ hip circumferences $(\mathrm{cm})$ were taken in session one, by three trained anthropometrists as previously described (Wall-Medrano et al., 2016). The following body composition indexes were calculated: Body mass index (BMI; $\left.\mathrm{kg} / \mathrm{m}^{2}\right)$, waist-to-hip ratio and body adiposity index using the validated equation reported by Bergman et al., (2011). Lastly, each subject's somatotype [endomorphy, mesomorphy, ectomorphy] was calculated according to the Heath \& Carter method (Carter, 2002) based on the following body measurements (right-side; test-retest, $r \geq 0.90$ ): body weight, height, skinfolds (triceps, subscapular, supraspinale, medial calf corrected for height), biepicondylar breadths (humerus, femur), girths (upper arm, calf), following all recommendations from the International Society for the Advancement of Kinanthropometry.

\section{Cardiorespiratory Fitness}

In session two, each subject performed a preliminary short cycle ergometer test (Monark ergomedic $828 \mathrm{E}$; Monark exercise AB, 105 Vansbro, Sweden) during which HR (beats.min ${ }^{-1}$ ) was measured with a Polar H7 
sensor (Polar Electro, Lake Success, NY), $\mathrm{VO}_{2}\left(\mathrm{~mL}_{\mathrm{kg}}{ }^{-1} \cdot \mathrm{min}^{-1}\right.$ or L.min ${ }^{-1}$ ) with a gas analyzer (Cortex MetaLyzer 3B, Germany) (Ramos-Jiménez et al., 2008; Ramos-Jiménez et al., 2013a). The gas analyzer was calibrated and corrected for barometric pressure, temperature and humidity before and during each test by using certified gas mixtures of known concentrations $\left[4 \%\left(\mathrm{CO}_{2}\right)-16 \%\left(\mathrm{O}_{2}\right)-80 \%\left(\mathrm{~N}_{2}\right) ; 26 \%\left(\mathrm{O}_{2}\right)-74 \%\left(\mathrm{~N}_{2}\right)\right]$. The equipment complied with all minimal requirements stated by the American Thoracic Society and the American College of Chest Physicians (American Thoracic Society, 2003) for dynamic exercise testing devices. Maximal threshold values for $\mathrm{HR}\left[\mathrm{HR}_{\mathrm{Max}}\left(\right.\right.$ beats.min $\left.\left.{ }^{-1}\right)\right]$ and $\mathrm{VO}_{2}[$ measured (Peak $) /$ calculated $\left(\mathrm{Max}_{2}\right) \mathrm{VO}_{2}\left(\mathrm{~mL} \mathrm{~kg}^{-1}\right.$. $\mathrm{min}^{-1}$ or L. $\mathrm{min}^{-1}$ ) were used to define the subject's fitness condition, following the American Heart Association standards for exercise testing and training (Fletcher et al., 2013; Jones et al., 1985).

\section{Submaximal eXercise test}

From the $3^{\text {rd }}$ to the $5^{\text {th }}$ session, participants performed three non-consecutive submaximal exercise tests for considering intra-individual variations in PE, HR and $\left[\mathrm{LA}^{-}\right]_{\mathrm{b}}$. The cycle-ergometer was fixed to the subjects' preferred hip angle in upright position, in order to avoid any discomfort that may affect its physical performance and PE during the test (Ashe et al., 2003). The submaximal exercise test consisted of the following protocol: Firstly, all subjects warmed up to 5 minutes while pedaling with no load. Afterwards, the exercise was initiated at a workload of 50-75 watts with increments of 20 (unfit subjects) or 30 (fit subjects) watts (Ramos-Jiménez et al., 2008) every three minutes for up to 15 minutes until evident exhaustion or when the subject pedaled at $\leq 40$ revolutions/min. The exercise was stopped when reaching $90 \%$ of the age-determined $\mathrm{HR}_{\mathrm{Max}}$.

\section{Borg's CATEgory Ratio-SCALE (CR-10)}

CR-10 scale was explained in session two before evaluating the subject's cardiorespiratory fitness (sessions 3-5). Psychosomatic fatigue was evaluated every three minutes using the verbal expressions for CR-10 (table 1) suggested by Borg (1982; et al., 1985). The scale (with no PE "labels") was wall-mounted just in front of the participant, and the rating was recorded every three minutes.

TABLE 1

Borg's category ratio-scale (CR-10)

\begin{tabular}{|llcl}
\hline Level & Perceived exertion ("label") & Level & Perceived exertion ("label") \\
\hline 0 & Nothing at all & 5.0 & Strong \\
0.5 & Very very weak (just noticeable) & 6.0 & \\
1.0 & Very weak & 7.0 & Very strong \\
2.0 & Weak (light) & 8.0 & \\
3.0 & Moderate & 9.0 & \\
4.0 & Somewhat strong & 10.0 & Very very strong (almost max) \\
\hline
\end{tabular}

Source: Borg (1982; et al., 1985; \& Kaijser, 2006). "Labels" are not displayed to the participant.

\section{BLOOD LACTATE}

$\left[\mathrm{LA}^{-}\right]_{\mathrm{b}}$ level $(\mathrm{mM})$ was assayed in an YSI 1500 Sport Lactate Analyzer (YSI life sciences, OH, U.S.A) as previously described (Ramos-Jiménez et al., 2013a). The onset of blood lactate accumulation (OBLA) was defined at $\left[\mathrm{LA}^{-}\right]_{\mathrm{b}}=4 \mathrm{mM}$ (Chmura \& Nazar, 2010) while the anaerobic threshold was defined in this study as the $\left[\mathrm{LA}^{-}\right]_{\mathrm{b}}$ at which the $90 \%$ of the age-determined $\mathrm{HR}_{\text {Max }}$ was reached. 


\section{Statistical aNALYsis}

Anthropometric data was firstly analyzed by usingSoftware LifeSize version 2.0 (NoldsSportsScientific; Australia). The following records were included in the statistical analysis: $a$ ) Records with complete anthropometric and physiological data $\left(\mathrm{BMI}+\mathrm{HR}+\mathrm{VO}_{2}+\left[\mathrm{LA}^{-}\right]_{\mathrm{b}}+\mathrm{CR}-10\right)$ and $\left.b\right)$ Records derived from complete submaximal exercise tests were the subject reached $90 \%$ of the age-determined $\mathrm{HR}_{\text {Max }}$ (Jones et al., 1985). Descriptive data were generated and reported as mean \pm SD after testing for normality. Differences in both anthropometric and physiological variables between normal weight $\left(B M I=18.5-24.9 \mathrm{~kg} / \mathrm{m}^{2}\right)$ and overweight/obese $\left(B M I \geq 25 \mathrm{~kg} / \mathrm{m}^{2}\right)$ were analyzed using 2-tailed, paired $t$ tests. Relationships between all physiological parameters and CR-10 ratings during submaximal exercise were examined firstly by using Pearson's product moment correlation coefficients. The best predicting equations (linear, quadratic, cubic, exponential or power) for CR-10 vs. HR and CR-10 vs. $\left[\mathrm{LA}^{-}\right]_{\mathrm{b}}$, were further generated by regression analysis using the maximum $R^{2}$ (goodness-of-fit) procedure as previously described (Wall-Medrano et al. 2016).

The reliability of HR (as \%HR max ) and CR-10 cut offs as independent predictors of OBLA was analyzed by their sensitivity (low false negatives) and specificity (low false positives) using crosstabs and receiving operating characteristic (ROC) curves. Stepwise linear regression was used to explore all possible relationships between CR-10, physiological $\left(\mathrm{HR}, \mathrm{VO}_{2 \max }\right.$ ) and anthropometric (mesomorphy, waist/hip ratio) variables and $\left[\mathrm{LA}^{-}\right]_{\mathrm{b}}$. All statistics were performed using IBM SPSS statistics 21.0 (Armonk, NY: IBM Corp). The alpha level was set at $p<0.05$.

\section{Results}

According to table 2, $49.5 \%$ of all participants were overweight/obese $\left(29.3 \pm 3.0 \mathrm{~kg} / \mathrm{m}^{2}\right)$, with a higher waist $(+16 \mathrm{~cm})$, hip $(+10.2 \mathrm{~cm})$, waist $/$ hip $(+0.1)$ and body adiposity index $(+4 \%)$ than normal-weight

TABLE 2

Anthropometric and physiological characteristics of participants

\begin{tabular}{|c|c|c|c|}
\hline & Total & Normal weight & Overweight-obes \\
\hline $\mathrm{N}$ & 91 & 46 & 45 \\
\hline Age $(y)^{*}$ & $24 \pm 4$ & $23 \pm 3$ & $25 \pm 5$ \\
\hline Body weight $(\mathrm{kg})^{* *}$ & $78.1 \pm 15.1$ & $68.0 \pm 8.3$ & $88.3 \pm 13.6$ \\
\hline Height (m) & $1.7 \pm 0.1$ & $1.7 \pm 0.1$ & $1.7 \pm 0.1$ \\
\hline Body mass index $\left(\mathrm{kg} / \mathrm{m}^{2}\right)^{* *}$ & $25.9 \pm 4.2$ & $22.5 \pm 1.7$ & $29.3 \pm 3.0$ \\
\hline Waist circumference $(\mathrm{cm})^{* *}$ & $82.1 \pm 11.0$ & $74.9 \pm 5.9$ & $90.9 \pm 9.1$ \\
\hline Hip circumference $(\mathrm{cm})^{* *}$ & $97.0 \pm 7.4$ & $92.4 \pm 4.6$ & $102.6 \pm 6.2$ \\
\hline Waist-to-hip ratio** & $0.8 \pm 0.1$ & $0.8 \pm 0.05$ & $0.9 \pm 0.1$ \\
\hline Waist-to-height ratio & $0.04 \pm 0.00$ & $0.04 \pm 0.00$ & $0.04 \pm 0.02$ \\
\hline Body adiposity index $(\%) * *$ & $24.3 \pm 3.5$ & $22.5 \pm 2.6$ & $26.5 \pm 3.2$ \\
\hline $\mathrm{VO}_{2 \operatorname{Max}}\left(\mathrm{L} \cdot \mathrm{min}^{-1}\right)$ & $3.8 \pm 0.3$ & $3.8 \pm 0.3$ & $3.9 \pm 0.4$ \\
\hline $\mathrm{VO}_{2 \text { Peak }}\left(\mathrm{L} \cdot \mathrm{min}^{-1}\right)$ & $3.7 \pm 0.8$ & $3.6 \pm 0.8$ & $3.7 \pm 0.8$ \\
\hline $\mathrm{VO}_{2}$ Peak $\left(\mathrm{mL} \cdot \mathrm{kg}^{-1} \cdot \mathrm{min}^{-1}\right)^{* *}$ & $46.6 \pm 11.9$ & $51.8 \pm 12.3$ & $40.7 \pm 8.3$ \\
\hline $\mathrm{VO}_{23 \min }\left(\mathrm{L} \cdot \mathrm{min}^{-1}\right)$ & $2.0 \pm 0.7$ & $2.0 \pm 0.6$ & $2.1 \pm 0.7$ \\
\hline $\mathrm{HR}_{\max }\left(\text { beats. } \mathrm{min}^{-1}\right)^{*}$ & $184.8 \pm 3.1$ & $185.8 \pm 2.3$ & $183.9 \pm 3.5$ \\
\hline $\mathrm{HR}_{3 \min }$ (beats.min ${ }^{-1}$ ) & $129.9 \pm 20.1$ & $131.0 \pm 22.5$ & $128.8 \pm 69.4$ \\
\hline $\mathrm{HR}_{3 \min }\left(\% \mathrm{HR}_{\max }\right)$ & $70.0 \pm 9.1$ & $70.6 \pm 9.9$ & $69.4 \pm 8.3$ \\
\hline$\left[\mathrm{LA}^{-}\right]_{\mathrm{b}} 3 \min (\mathrm{mM})$ & $2.6 \pm 0.9$ & $2.7 \pm 0.9$ & $2.5 \pm 0.9$ \\
\hline
\end{tabular}

Data is expressed as mean \pm SD. Statistical differences between normal and overweight/obese individuals at $p \leq 0.002\left({ }^{*}\right)$ or $p<0.0001\left(^{* *}\right)$; heart rate $(\mathrm{HR})$, oxygen uptake $\left(\mathrm{VO}_{2}\right)$ and/or lactate $\left[\mathrm{LA}^{-}\right]_{\mathrm{b}}$ measured at minute three $(3 \mathrm{~min})$ or highest measured (Peak) or calculated (Max) level. 
subjects $(p<0.001)$. The two-dimensional somato chart (figure 1 ) shows two clearly differentiated somato types for normal-weight (1-central; $x=0, y=2.8$ ) and overweight/obese (2- endomorph/mesomorph; $x=$ $-4, y=6.8)$ subjects with a quasi-linear distribution along the mesomorph axis. Although overweight/obese subjects showed a lower $\mathrm{HR}$ Max $\left(-1.9\right.$ beats.min $\left.{ }^{-1}\right)$ and $\mathrm{VO}_{2}$ Peak $\left(-11.4 \mathrm{~mL} \cdot \mathrm{kg}^{-1} \cdot \mathrm{min}^{-1}\right)$ at the end of submaximal exercise test than normal-weight subjects $(p \leq 0.002)$, all other cardiorespiratory fitness indicators were not different $(p>0.05)$ including their physiological response three minutes after being initiated the submaximal exercise protocol: $\mathrm{HR}_{3 \text { min }}\left(\sim 130\right.$ beats. $\left.\mathrm{min}^{-1} ; \sim 71 \% \mathrm{HR}_{\max }\right),\left[\mathrm{LA}^{-}\right]_{\mathrm{b}}(2.6 \mathrm{mM})$. Both, normal weight and overweight subjects performed submaximal exercise tests at a $\mathrm{VO}_{2 \text { peak }}$ (experimental) $/ \mathrm{VO}_{2} \max$ (calculate) ratio of $95 \%$.

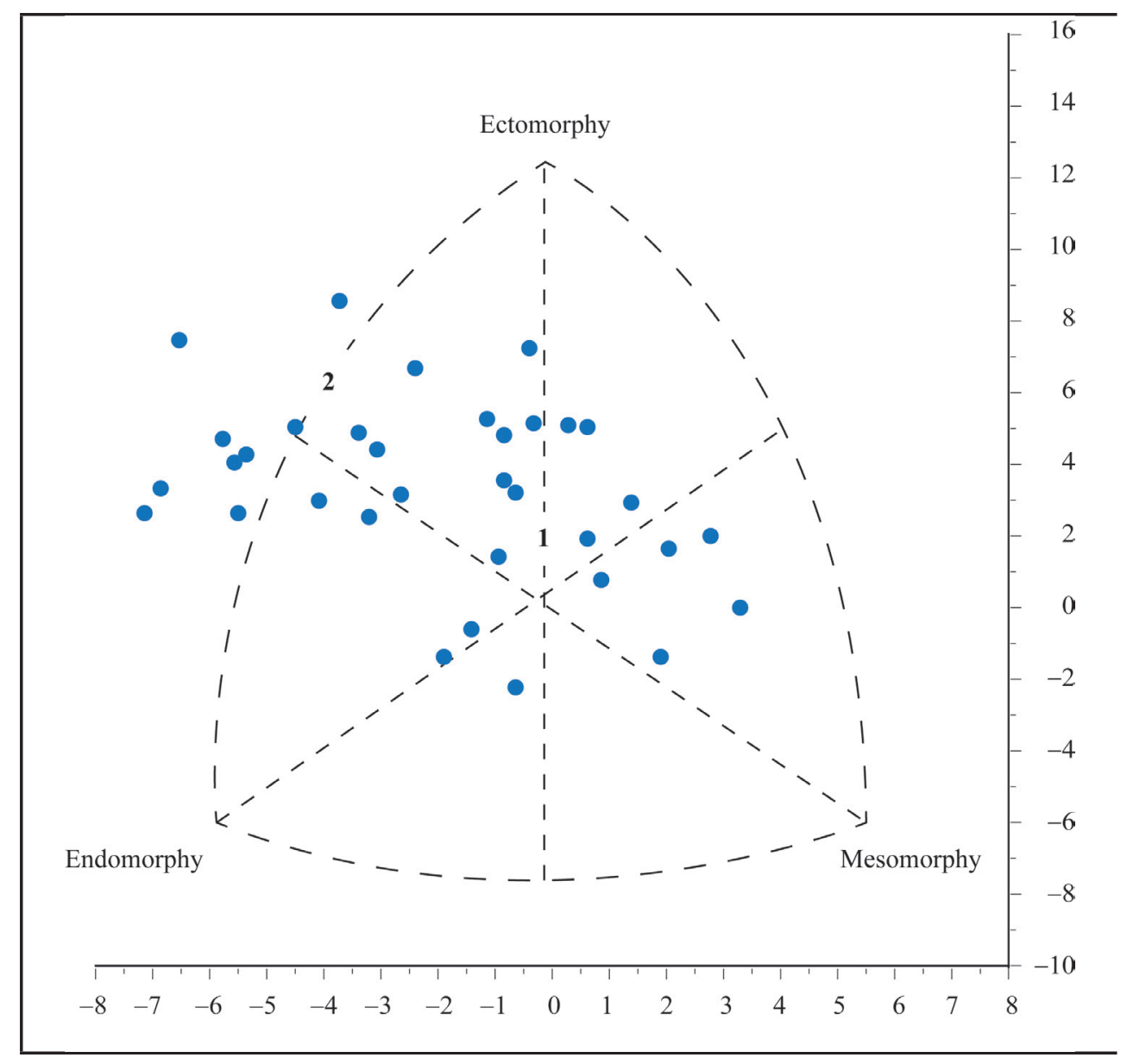

FIGURE 1

Somatochart of participants.

Footnote: Mean somatotype for normal weight (1) and overweight/obese (2) subjects.

Simple linear regression analysis (figure 2) showed coefficients of determination $\left(R^{2}\right)$ between $0.65-0.73$ (HR/ CR-10), 0.54-0.66 ([LA- $\left.]_{\mathrm{b}} / \mathrm{CR}-10\right)$ and 0.25-0.34 $\left(\mathrm{VO}_{2 \max } / \mathrm{CR}-10\right)$ (figure 1) with no significant effect related to body weight status $(p>0.05)$. Further regression analyses using the $R^{2}$-goodness of fit procedure confirmed the linear relationship between $\mathrm{HR}$ and CR-10 (see equation in figure 1 ) while $\left[\mathrm{LA}^{-}\right]_{\mathrm{b}}$ $v$ s. CR-10 fitted a polynomial model: $\left[\mathrm{LA}^{-}\right]_{\mathrm{b}}=2.10(\mathrm{CR}-10)-0.36(\mathrm{CR}-10)^{2}+0.023(\mathrm{CR}-10)^{3}\left(R^{2}=0.92\right.$; $p<0.01$ ) with no significant effect related to body weight status. However, the $\mathrm{VO}_{2}$ max $/ \mathrm{CR}-10$ statistical relationship did not improve with the $R^{2}$-goodness of fit method. 


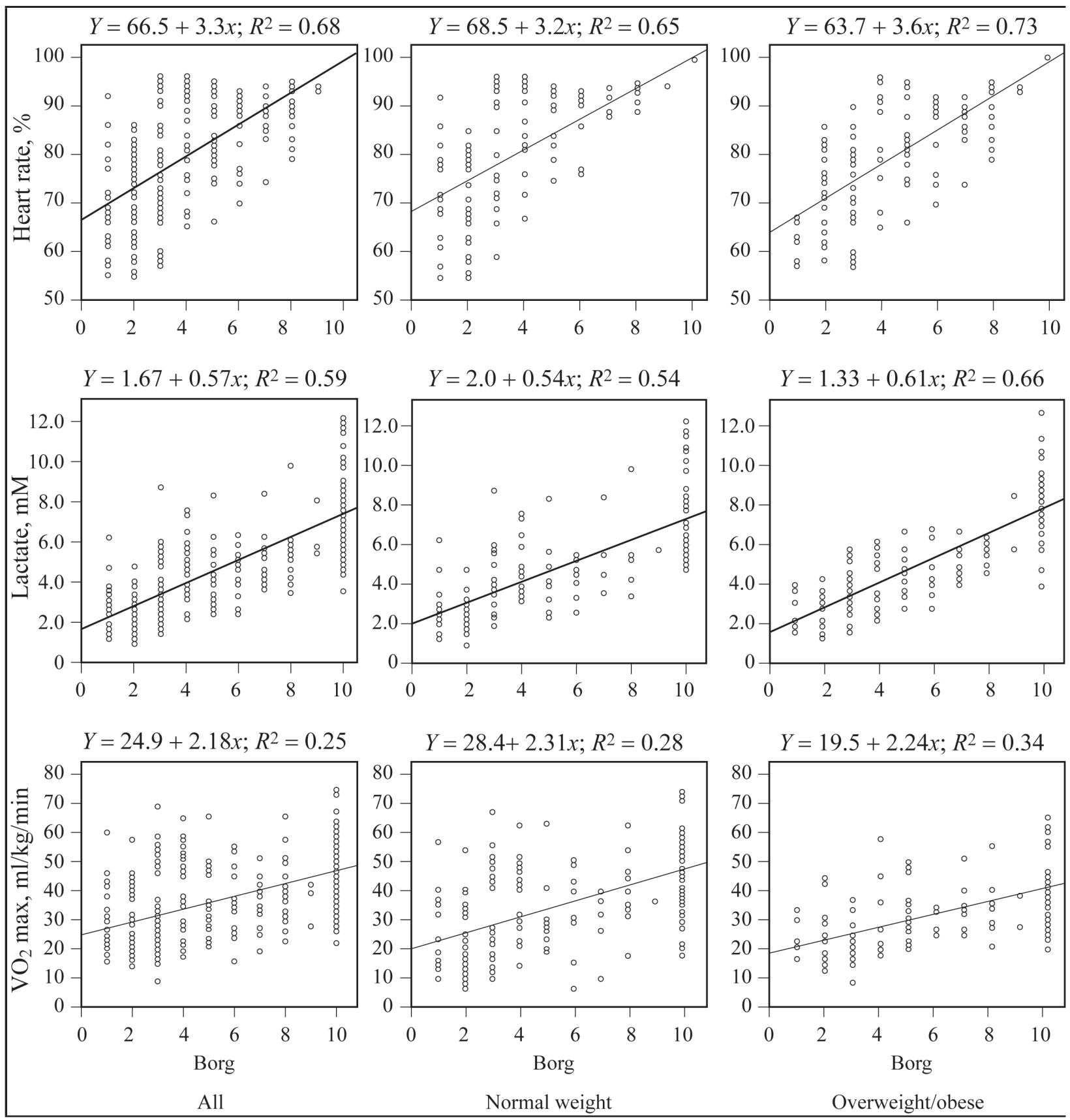

FIGURE 2

Linear regression between Borg's category ratio-scale (CR-10), heart rate $(\mathrm{HR})$, blood lactate $\left[\mathrm{LA}^{-}\right]_{\mathrm{b}}$ and maximal oxygen uptake $\left(\mathrm{VO}_{2} \max \right)$.

TABLE 3

Onset of blood lactate accumulation (OBLA)

\begin{tabular}{|lcc}
\hline & $\mathrm{HR}^{\mathrm{a}}$ & $\mathrm{CR}-10^{\mathrm{b}}$ \\
\hline OBLA cutoff & 86.5 & 4.5 \\
Sensitivity & 0.84 & 0.80 \\
Specificity & 0.90 & 0.81 \\
Area under the curve & 92.3 & 90.2 \\
\hline
\end{tabular}

Footnote: a \% of maximal heart rate $\left(\mathrm{HR}_{\max }\right) \cdot{ }^{\mathrm{b}}$ Borg's category ratio-scale $(\mathrm{CR}-10)$ 
OBLA related cutoffs for \% $\mathrm{HR}_{\max }$ and CR-10 were 86.5 and 4.5, respectively (table 3 ), showing almost the same sensitivity and specificity $(r=0.80-0.91$, AUC > 90\%). In fact, subjects that specifically declared a CR-10 rating of 4 or 5, did it 6-9 minutes after having initiated the submaximal exercise, although overweight/ obese subjects (figure 3, circles) reached this $\mathrm{PE}$ at a little bit lower $\% \mathrm{HR}_{\max }$ than normal weight subjects (figure 3, diamonds).

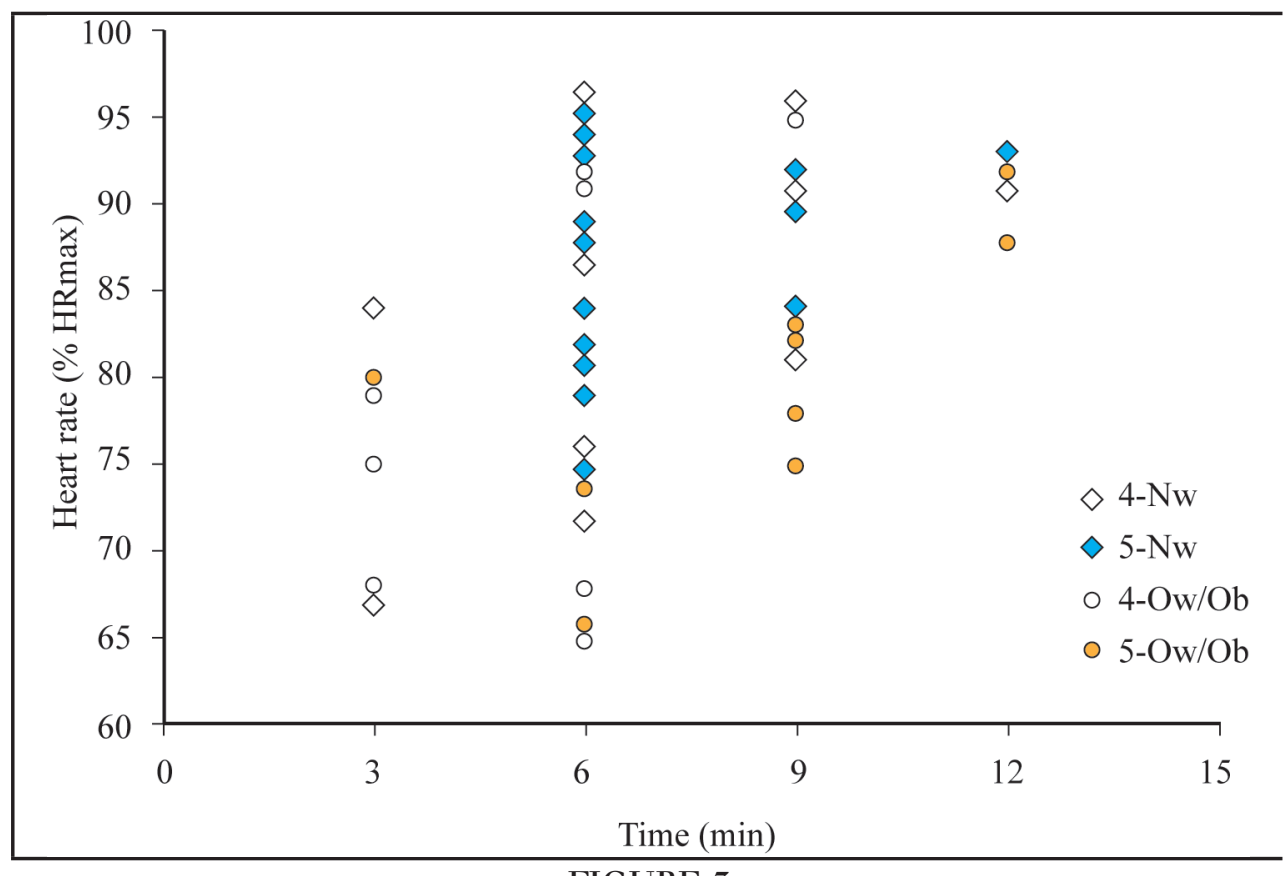

FIGURE 3

CR-10 ratings at OBLA for normal $(\mathrm{Nw})$ and overweight/obese $(\mathrm{Ow} / \mathrm{Ob})$ subjects Footnote: Onset of blood lactate accumulation (OBLA) CR-10's range (4-5).

Lastly, CR-10, \% $\mathrm{HR}_{\text {max }}$, mesomorphy and $\mathrm{VO}_{2 \text { max }}$, independently explained $>60 \%$ of the associated variance to $\left[\mathrm{LA}^{-}\right]_{\mathrm{b}}$, according to the following equations: A) $\left[\mathrm{LA}^{-}\right]_{\mathrm{b}}=0.38(\mathrm{CR}-10)+0.14$ (mesomorphy) $+0.033(\mathrm{HR})-3.17\left(R^{2}=0.64\right)$ and, $\left.\mathrm{B}\right)\left[\mathrm{LA}^{-}\right]_{\mathrm{b}}=5.78($ waist $/$ hip $)+0.38(\mathrm{CR}-10)+0.06\left(\mathrm{VO}_{2 \max }\right)+$ $0.01(\mathrm{HR})-6.44 ;\left(R^{2}=0.69\right)$.

\section{Discussion}

The public invitation strategy used in this study led to the recruitment of 91 subjects from which $~ 50 \%$ was overweight/obese with a central adiposity and endomorph/mesomorph phenotype. Obesity is a major health problem for the Mexican health system (Wall-Medrano et al., 2016); due to its high prevalence and negative outcomes, physicians often recommend increasing the level of physical activity plus several dietary modifications, as part of an overall lifestyle change (Galaviz et al., 2015; Jauregui et al., 2015). The National Agreement for Nutritional Health has provided the basis to create a sustainable national policy toward a healthier food system while other proactive actions have been implemented by the private sector to promote systematic physical activity (Jauregui et al., 2015). However, there is still a long way to go in terms of reducing the trend of sedentary lifestyle among young Mexicans despite the fact that at this age body image dissatisfaction is an important determinant for sports practicing (Ramos-Jiménez et al., 2017) and exercising in fitness centers (Baile Ayensa et al., 2011).

It is noteworthy that young subjects are more prone to modify their physical activity level than adults (Hallal et al., 2012), since it is a more socially-accepted way for body weight management; this is why 
the fitness market focuses on the young user of these services (Club Intel, 2016). However, desertion and attrition to physical activity programs by subjects with excess body weight is high (Ekkekakis \& Lind, 2006; Miller \& Brennan, 2015), particularly in those performed at a high intensity such as spinning and highintensity interval exercise. Moreover, the odds of injuries attributed to exercise increases 6-10\% for each BMI unit, regardless the type of prescribed exercise (Janney \& Jakicic, 2010), a fact that affect the subject's perception of risk/benefit of practicing systematic exercise. Anyhow, the observed high participation in this study probably resulted from the health awareness efforts made by the program healthy university, a comprehensive program that fosters academic performance by improving health and quality of life of students (Wall-Medrano et al., 2016), in which promotion of physical activity is a straightforward component.

The fitness status of overweight/obese and normal-weight subjects was quite similar at the beginning but not at the end of the submaximal exercise test, where a lower $\mathrm{HR}_{\max }$ and $\mathrm{VO}_{2}$ Peak was observed in overweight/ obese subjects; this in turn seemed to affect their PE since both groups declared the same CR-10 rating (4 to $5)$ at almost the same time frame (6-9 min) but with a little bit different \% $\mathrm{HR}_{\max }$. According to Ekkekakis $\&$ Lind (2006), self-selected and imposed (10\% > self-selected) intensity affect the PE and pleasantness of a constant $(20 \mathrm{~min})$ treadmill exercise in overweight adult women; they also demonstrated that overweight women exercised at a higher $\mathrm{VO}_{2}$ Peak than their normal-weight counterparts. However, the relationship between PE with $\mathrm{HR}_{\max }$ or $\mathrm{VO}_{2}$ max is also age and sex specifically (Loe et al., 2013). According to Hetlelid et al. (2015) the cardiorespiratory performance $\left(93-95 \% \mathrm{HR}_{\max }\right.$ ) and PE of well-trained and recreationallytrained male subjects after a session of high intensity interval exercise, is quite similar, increasing their $\left[\mathrm{LA}^{-}\right]$ $\mathrm{b}$ to the same extent $(\sim 6.3 \mathrm{mM})$ but differing in their fat utilization. In our study both groups behave the same in the submaximal exercise test $\left(\mathrm{VO}_{2 \text { peak }} / \mathrm{VO}_{2 \text { max }}\right.$ ratio $\left.~ 95 \%\right)$, but the extent to which body fat was used is unknown.

From a physiological stand point, any exercise should be performed at a sufficient intensity in as much time as possible $(\geq 30 \mathrm{~min}$ ), allowing an energy expenditure mainly from body fat reserves (Horowitz \& Klein 2000). To achieve this, the person should work at enough submaximal workload without exceeding the anaerobic threshold, since above this point the body switches its substrate utilization increasing the use of carbohydrates instead of fats (Ramos-Jiménez et al., 2008; Zamunér et al., 2011). In this sense, $\left[\mathrm{LA}^{-}\right]_{\mathrm{b}}$ becomes the parameter of choice to detect with a greater sensitivity and specificity the anaerobic threshold. It should be clarified that $\mathrm{aVO}_{2}$ above when the energy is supplied by anaerobic mechanisms (lactate/pyruvate ratio increases) causing a steady-state $\left[\mathrm{LA}^{-}\right]_{\mathrm{b}}$ level, glycogen depletion and metabolic acidosis is known as anaerobic threshold while OBLA (4 mM) is a preceding condition (Beneke et al., 2011; Borg et al., 1985). In fact, the exercise intensity at OBLA is $60-70 \%$ of submaximal workload while for anaerobic threshold is $\geq 83 \%$ where the threshold of psychomotor fatigue occurs (Chmura \& Nazar, 2010) associated to a higher $p \mathrm{CO}_{2}$ and adrenaline/nor-adrenaline response (Munch et al., 2014). In this study, $\left[\mathrm{LA}^{-}\right]_{\mathrm{b}}$ was similar among groups three minutes after the submaximal exercise test started; however, $\left[\mathrm{LA}^{-}\right]_{\mathrm{b}}$ level increased more homogenous in the overweight/obese group although at a higher rate $(m=0.61)$ than normal-weight subjects $(m=0.54)$, reaching a maximal PE with a wider range of $\left[\mathrm{LA}^{-}\right]_{\mathrm{b}}$ level than normal-weight subjects. Many physiological factors can explain this differential $\left[\mathrm{LA}^{-}\right]_{\mathrm{b}}$ response including differences in glucose oxidative capacity associated to insulin resistance, mitochondrial functionality and the fact that adipose tissue is a significant source of lactate (Adeva-Andany et al., 2014; Jansson et al., 1994), particularly in overweight/ obese individuals.

Besides $\left[\mathrm{LA}^{-}\right]_{\mathrm{b}}$, there are other ways to evaluate the exercise intensity; mean blood pressure, body temperature, $\mathrm{HR}, \mathrm{VO}_{2}$ are just some examples (Borg, 1982; Ramos-Jiménez et al., 2013b). However, despite the fact that most of them show a good correlation with $\left[\mathrm{LA}^{-}\right]_{\mathrm{b}}$ (Adeva-Andany et al., 2014), their usefulness in the daily practice in most fitness centers is questionable because of their invasiveness. In this case, PE scales 
such as those developed by Borg (et al 1985; \& Kaijser, 2006) could be very useful. It should be remembered at this point, that PE results from integrating many symptoms associated with homeostatic to increasing exercise, come from the skeletal muscle (e.g. $\left[\mathrm{LA}^{-}\right]_{\mathrm{b}}$ ), cardiovascular (e.g. HR, blood pressure), respiratory (e.g. $\mathrm{VO}_{2 \text { max }}$ and RER) and nervous (e.g. discomfort) systems (Chmura \& Nazar, 2010). That is why, CR-10 has been particularly useful for exercise prescription, training and rehabilitation in addition, its correlation with other PE scales such as the visual analogue scale (Capodaglio, 2001) is high.

The linear relationship between PE, $\mathrm{HR}, \mathrm{VO}_{2} \max$ and $\left[\mathrm{LA}^{-}\right]_{\mathrm{b}}$ in heavy exercising has been studied in healthy active subjects (Borg, 1982; Dantas et al., 2015; Ramos-Jiménez et al., 2013b) and aerobiccompromised people (Coquart et al., 2015). However, studies on the relationship of [ $\left.\mathrm{LA}^{-}\right]_{\mathrm{b}}$ at AT or OBLA points are scarce (Chmura \& Nazar, 2010; Zamunér et al., 2011). In this investigation we observed that a CR-10 cutoff value of 4.5 (somewhat strong-to-strong) or $86.5 \%$ of the $\mathrm{HR}_{\text {max }}$ are both reliable to predict OBLA. Both validated cutoffs are useful to prescribe and even evaluate the exercise intensity before reaching the AT (50-70\%, $\mathrm{VO}_{2 \text { max }}$ ) (Ramos-Jiménez et al., 2013a) for people who wishes to get cardiorespiratory fitness or to lose weight. Moreover, CR-10 is useful to predict OBLA regardless the subject's body weight: when substituting the CR-10 optimized value (4.5) in the lineal and polynomial equations generated in this study, a $\left[\mathrm{LA}^{-}\right]_{\mathrm{b}}$ level of 4.24 and 4.26 is obtained respectively and the stepwise-lineal regression equations developed in this study supports CR-10 as the most influencing variable on [ $\left.\mathrm{LA}^{-}\right]_{\mathrm{b}}$. To our knowledge, this is the first report on the statistical relationship between body shape indicators (mesomorphy and waist/hip ratio) and $\left[\mathrm{LA}^{-}\right]_{\mathrm{b}}$. In support of this, it is well-known that the higher the muscularity (endomorphy) (Van Hall, 2010) or body fat (Adeva-Andany et al., 2014; Jansson et al., 1994) the higher the [ $\left.\mathrm{LA}^{-}\right]_{\mathrm{b}}$. level and we also observed an inverse relationship between waist circumference and $\mathrm{VO}_{2 \max }(r=-0.25, p<0.01$; data not shown), which in turn justifies why body organs from overweight/obese subjects may have produced more lactate than normal-weight subjects.

In conclusion, a CR-10 cutoff of 4.5 is useful to predict OBLA ( $4 \mathrm{mM}$ ) with almost the same reliability than HR (convergent validity) during a submaximal exercise test, regardless the subject's body weight. All prospective equations developed in this study sustain the positive relationship between CR-10 ratings and $\left[\mathrm{LA}^{-}\right]_{\mathrm{b}}$ but specific body shape indicators of muscularity (mesomorphy) or central adiposity (high waist circumference) are important predictors.

\section{Strengths \& Limitations}

Lastly, the authors recognize that this study has sources of potential bias or imprecisions that may comprise the generalizability of its results. First, the promotion strategy used to recruit participants, caused a higher prevalence of overweigh/obesity in the sample than that observed for the same student community (Villalobos-Molina et al., 2015; Wall-Medrano et al., 2016). Second, cleaning data records derived from submaximal exercise tests that did not reach $90 \%$ of the subject's age-determined $\mathrm{HR}_{\max }$ (Jones et al., 1985) this may have resulted in the selection of "fit but fat" cases (Loprinzi et al., 2014). Third, the submaximal exercise test was performed in a cycle-ergometer and so, the results could only be applied to exercises of the same nature performed at low (group cycling) or high (spinning) intensity. Fourth, it is well-known targeting OBLA (or any specific $\left[\mathrm{LA}^{-}\right]_{\mathrm{b}}$ level; Held \& Marti, 1999) or pre-fixing a standard submaximal exercise test does not merely mean the same exercise intensity or PE rating among well $v$ s. poorly endurance-trained subjects and so the ratio of 15\%-to-85\% of trained vs. un-trained individuals could be underrating the power of CR-10 in the case of trained individuals. Despite these limitations, the value of this study not only relies on the fact that CR-10 is useful to predict OBLA in similar populations (young adults) but also provides a startup platform to evaluate the effect of the aforementioned counterpoints, in order to test the external validity of CR-10 vs. OBLA. 


\section{Prospective analysis}

Exercise science should be available to anyone who wants to physically exercise. The Borg scale is a subjective, however practical instrument and simple to use, which allows us to graduate the exercise, so that we can work at known intensities, aerobic or anaerobic, either to lose weight, to strengthen the cardiovascular system or both. Given its usefulness, any coach and sports center that is considered respectable should include this tool when imparting physical activity. However, in order to maximize the OBLA-predicting value of CR-10 reported here, further studies are required in young people from other regions of Mexico; without doubt, more than a limitation of the study, it is a contribution that will prompt other research groups of Mexico to extend the external validation of CR-10.

\section{Ethical CONSIDERATiOnS}

The submaximal exercise protocol (including all secondary physiological outcomes) was initially approved by the Institutional Ethics Committee of the Autonomous University of Ciudad Juarez. After receiving a detailed explanation of all experimental procedures and purpose of the observational study, including information on the nature of the submaximal exercise test, end-point symptoms and possible complications (Fletcher et al., 2013), each participant signed a written and informed consent in compliance with the declaration of Helsinki.

\section{REFERENCES}

Adeva-Andany, M., López-Ojén, M., Funcasta-Calderón, R., Ameneiros-Rodríguez, E., Donapetry-García, C., Vila-Altesor, M., \& Rodríguez-Seijas, J. (2014). Comprehensive review on lactate metabolism in human health. Mitochondrion, 17, 76-100. 10.1016/j.mito.2014.05.007

American Thoracic Society. (2003). ATS/ACCP statement on cardiopulmonary exercise testing. American Journal of Respiratory and Critical Care Medicine, 167(2), 211. 10.1164/ajrccm.167.10.950

Ashe, M. C., Scroop, G. C., Frisken, P. I., Amery, C. A., Wilkins, M. A., \& Khan, K. M. (2003). Body position affects performance in untrained cyclists. British Journal of Sports medicine, 37(5), 441-444. 10.1136/ bjsm.37.5.441

Baile Ayensa, J. I., González Díaz, A., Ramírez Ortiz, C., \& Suarez Andujo, P. (2011). Imagen corporal, hábitos alimentarios y hábitos de ejercicio físico en hombres usuarios de gimnasio y hombres universitarios no usuarios. Revista de Psicología del Deporte, 20(2), 353-366.

Beneke, R., Leithäuser, R. M., \& Ochentel, O. (2011). Blood lactate diagnostics in exercise testing and training. International Journal of Sports Physiology and Performance, 6(1), 8-24.

Bergman, R. N., Stefanovski, D., Buchanan, T. A., Sumner, A. E., Reynolds, J. C., Sebring, N. G.,... \& Watanabe, R. M. (2011). A better index of body adiposity. Obesity, 19(5), 1083-1089. 10.1038/oby.2011.3

Borg, G. A. (1982). Psychophysical bases of perceived exertion. Medicine and Science and Sports Exercise, 14(5), 377-381.

Borg, E., \& Kaijser, L. (2006). A comparison between three rating scales for perceived exertion and two different work tests. Scandinavian Journal of Medicine \& Science in Sports, 16(1), 57-69. 10.1111/j.16000838.2005.00448.x 
Borg, G., Ljunggren, G., \& Ceci, R. (1985). The increase of perceived exertion aches and pain in the legs, heart rate and blood lactate during exercise on a bicycle ergometer. European Journal of Applied Physiology and Occupational Physiology, 54(4), 343-349.

Capodaglio, E. M. (2001). Comparison between the CR10 Borg's scale and the VAS (visual analogue scale) during an arm-cranking exercise. Journal of Occupational Rehabilitation, 11(2), 69-74. 10.1023/A:1016649717326

Carter, J. E. L. (2002). The Heath-Carter Anthropometric Somatotype-Instruction Manual. Department of Exercise and Nutritional Science. USA. Retrieved from: http://www.somatotype.org/Heath-CarterManual.pdf

Club Intel. (2016). International Fitness Industry Trend Report, What's all the rage? A comprehensive study of global fitness industry behavior. Retrieved from http://www.club-intel.com/wp-content/uploads/2016-International-Fitness-Industry-Trend-Report.pdf.

Coquart, J. B., Eston, R. G., Lemaître, F., Bart, F., Tourny, C., \& Grosbois, J. M. (2015). Prediction of peak oxygen uptake from ratings of perceived exertion during a sub-maximal cardiopulmonary exercise test in patients with chronic obstructive pulmonary disease. European Journal of Applied Physiology, 115(2), 365-372. 10.1007/s00421-014-3023-6

Chmura, J., \& Nazar, K. (2010). Parallel changes in the onset of blood lactate accumulation (OBLA) and threshold of psychomotor performance deterioration during incremental exercise after training in athletes. International Journal of Psychophysiology, 75(3), 287-290. 10.1016/j. ijpsycho.2009.12.011

Dantas, J. L., Doria, C., Rossi, H., Rosa, G., Pietrangelo, T., Fanò-Illic, G., \& Nakamura, F. Y. (2015). Determination of blood lactate training zone boundaries with rating of perceived exertion in runners. The Journal of Strength \& Conditioning Research, 29(2), 315-320. 10.1519/JSC.0000000000000639

Dinger, M. K., Behrens, T. K., \& Han, J. L. (2006). Validity and reliability of the International Physical Activity Questionnaire in college students. American Journal of Health Education, 37(6), 337-343. 10.1080/19325037.2006.10598924

Edvardsen, E., Hem, E., \& Anderssen, S. A. (2014). End criteria for reaching maximal oxygen uptake must be strict and adjusted to sex and age: a cross-sectional study. PLOS ONE, 9(1). e85276. 10.1371/journal. pone.0085276

Ekkekakis, P., \& Lind, E. (2006). Exercise does not feel the same when you are overweight: the impact of selfselected and imposed intensity on affect and exertion. International Journal of Obesity, 30, 652-660. 10.1038/sj.ijo.0803052

Fletcher, G. F., Ades, P. A., Kligfield, P., Arena, R., Balady, G. J., Bittner, V. A., ... \& Gulati, M. (2013). Exercise standards for testing and training. Circulation, 128(8), 873-934. 10.1161/CIR.0b013e31829b5b44

Galaviz, K. I., Jauregu-Ulloa, E., Fabrigar, L. R., Latimer-Cheung, A., Lopez y Taylor, J., \& Lévesque, L. (2015). Physical activity prescription among Mexican physicians: a structural equation analysis of the theory of planned behaviour. International Journal of Clinical Practice, 69(3), 375-383. 10.1111/ijcp.12546

Hallal, P. C., Andersen, L. B., Bull, F. C., Guthold, R., Haskell, W., Ekelund, U., \& Lancet Physical Activity Series Working Group. (2012). Global physical activity levels: surveillance progress, pitfalls, and prospects. The Lancet, 380(9838), 247-257. 10.1016/S0140-6736(12)60646-1

Held, T., \& Marti, B. (1999). Substantial influence of level of endurance capacity on the association of perceived exertion with blood lactate accumulation. International Journal of Sports Medicine, 20(01), 34-39. $0.1055 /$ s-2007-971088 
Hetlelid, K. J., Plews, D. J., Herold, E., Laursen, P. B., \& Seiler, S. (2015). Rethinking the role of fat oxidation: substrate utilisation during high-intensity interval training in well-trained and recreationally trained runners. BMJ Open Sport \& Exercise Medicine, 1(1), e000047. 10.1136/bmjsem-2015-000047

Horowitz, J. F., \& Klein, S. (2000). Lipid metabolism during endurance exercise. The American Journal of Clinical Nutrition, 72(2), 558s-563s.

Janney, C. A., \& Jakicic, J. M. (2010). The influence of exercise and BMI on injuries and illnesses in overweight and obese individuals: a randomized control trial. International Journal of Behavioral Nutrition and Physical Activity, 7(1), 1. 10.1186/1479-5868-7-1

Jansson, P. A., Larsson, A., Smith, U., \& Lönnroth, P. (1994). Lactate release from the subcutaneous tissue in lean and obese men. Journal of Clinical Investigation, 93(1), 240-246. 10.1172/JCI116951

Jauregui, E., Pacheco, A. M., Soltero, E. G., O’Connor, T. M., Castro, C. M., Estabrooks, P. A.,... \& Lee, R. E. (2015). Using the RE-AIM framework to evaluate physical activity public health programs in México. BMC Public Health, 15(1), 162. 10.1186/s12889-015-1474-2

Jones, N. L., Makrides, L., Hitchcock, C., Chypchar, T., \& McCartney, N. (1985). Normal Standards for an Incremental Progressive Cycle Ergometer Test 1-3. American Review of Respiratory Disease, 131(5), 700 708. 10.1164/arrd.1985.131.5.700

Loe, H., Rognmo, Ø., Saltin, B., \& Wisløff, U. (2013). Aerobic capacity reference data in 3816 healthy men and women 20-90 years. PLOS ONE, 8(5), e64319. 10.1371/journal.pone.0064319

Loprinzi, P., Smit, E., Lee, H., Crespo, C., Andersen, R., \& Blair, S. N. (2014). The "fit but fat" paradigm addressed using accelerometer-determined physical activity data. North American Journal of Medical Sciences, 6(7), 295-301. 10.4103/1947-2714.136901

Miller, B. M., \& Brennan, L. (2015). Measuring and reporting attrition from obesity treatment programs: A call to action! Obesity Research \& Clinical Practice, 9(3), 187-202. 10.1016/j.orcp.2014.08.007

Munch, G. D. W., Svendsen, J. H., Damsgaard, R., Secher, N. H., González-Alonso, J., \& Mortensen, S. P. (2014). Maximal heart rate does not limit cardiovascular capacity in healthy humans: insight from right atrial pacing during maximal exercise. The Journal of Physiology, 592(2), 377-390. 10.1113/jphysiol.2013.262246

Muyor, J. M. (2013). Exercise intensity and validity of the ratings of perceived exertion (Borg and OMNI Scales) in an indoor cycling session. Journal of Human Kinetics, 39(1), 93-101. 10.2478/hukin-2013-0072.

Ramos-Jiménez, A., Hernández-Torres, R. P., Torres-Durán, P. V., Romero-Gonzalez, J., Mascher, D., PosadasRomero, C., \& Juárez-Oropeza, M. A. (2008). The respiratory exchange ratio is associated with fitness indicators both in trained and untrained men: a possible application for people with reduced exercise tolerance. Clinical Medicine. Circulatory, Respiratory and Pulmonary Medicine, 2, 1-9.

Ramos-Jiménez, A., Hernández-Torres, R. P., Urquidez-Romero, R., Wall-Medrano, A., \& Villalobos-Molina, R. (2017). Body Image Satisfaction as a Physical Activity Indicator in University Students. American Journal of Health Behavior, 41(5), 599-607. 10.5993/AJHB.41.5.9

Ramos-Jiménez, A., Hernández-Torres, R.P., Wall-Medrano, A., Juarez-Oropeza, M.A., \& Vera-Elizalde, M. (2013a). Blood lactate kinetics on passive and active recovery. Gazzetta Medica Italiana, 172(5), 343 350. Retrieved from: http://www.minervamedica.it/en/journals/gazzetta-medica-italiana/article. php?cod=R22Y2013N05A0343.

Ramos-Jiménez, A., Hernández-Torres, R. P., Wall-Medrano, A., Torres-Durán, P. V., Juárez-Oropeza, M. A., Viloria, M., \& Villalobos-Molina, R. (2013b). Gender-and hydration-associated differences in the physiological response to spinning. Nutrición Hospitalaria, 29(3), 644-651. 10.3305/ nh.2014.29.3.7017 
Van Hall, G. (2010). Lactate kinetics in human tissues at rest and during exercise. Acta Physiologica, 199(4), 499508. 10.1111/j.1748-1716.2010.02122.x

Villalobos-Molina, R., Wall-Medrano, A., Rodríguez-Tadeo, A., Urquidez-Romero, R., Hernández-Torres, R. P., Murguía-Romero, M.,... \& Díaz-Torres, B. A (2015). Hypertriglyceridemic-Waist (HTGW) phenotype in university students from two regions of Mexico. Acta Medica Mediterranea. 31, 173-178.

Wall-Medrano, A., Ramos-Jiménez, A., Hernandez-Torres, R. P., Villalobos-Molina, R., Tapia-Pancardo, D. C., Jiménez-Flores, J. R.,... \& Urquídez-Romero, R. (2016). Cardiometabolic risk in young adults from northern Mexico: Revisiting body mass index and waist-circumference as predictors. BMC Public Health, 16(1), 236. 10.1186/s12889-016-2896-1.

Zamunér, A. R., Moreno, M. A., Camargo, T. M., Graetz, J. P., Rebelo, A. C., Tamburús, N. Y., \& da Silva, E. (2011). Assessment of subjective perceived exertion at the anaerobic threshold with the Borg CR-10 scale. Journal of Sports Science \& Medicine, 10(1), 130-136.

\section{Abbreviations}

BMI: Body mass index

CR-10: Borg's category ratio-scale

HR: Heart rate

$\mathrm{HR}_{\text {max }}$ : maximal HR

$\left[\mathrm{LA}^{-}\right]_{\mathrm{b}}$ : Blood lactate

OBLA: Onset of blood lactate accumulation

PE: Perceived exertion

ROC: Receiving operating characteristics

$\mathrm{VO}_{2}$ : Oxygen uptake

$\mathrm{VO}_{2 \text { max }}$ : Maximal $\mathrm{VO}_{2}$ (calculated)

$\mathrm{VO}_{2}$ peak: Maximal $\mathrm{VO}_{2}$ (measured)

\section{BY-NC-N}

